\title{
'Predatory' Open Access Journals as Parody: Exposing the Limitations of 'Legitimate' Academic Publishing
}

\author{
Kirsten Bell
}

\section{University of British Columbia, kibell@mail.ubc.ca}

\begin{abstract}
The concept of the 'predatory' publisher has today become a standard way of characterising a new breed of open access journals that seem to be more concerned with making a profit than disseminating academic knowledge. This essay presents an alternative view of such publishers, arguing that if we treat them as parody instead of predator, a far more nuanced reading emerges. Viewed in this light, such journals destabilise the prevailing discourse on what constitutes a 'legitimate' journal, and, indeed, the nature of scholarly knowledge production itself. Instead of condemning them outright, their growth should therefore encourage us to ask difficult but necessary questions about the commercial context of knowledge production, prevailing conceptions of quality and value, and the ways in which they privilege scholarship from the 'centre' and exclude that from the 'periphery'.
\end{abstract}

Keywords: Open Access Publishers, Predatory Journals, Academic Publishing, Parody, Mimicry

Acknowledgement: An earlier version of this paper was written for the Technology and Evolving Forms of Publishing course at Simon Fraser University and thanks are due to Juan Pablo Alperin and Jessica Riches for their helpful feedback on the piece, which informed its final iteration. Thanks also to the two anonymous triple $C$ reviewers for their comments on the paper, which helped to strengthen the arguments presented. 


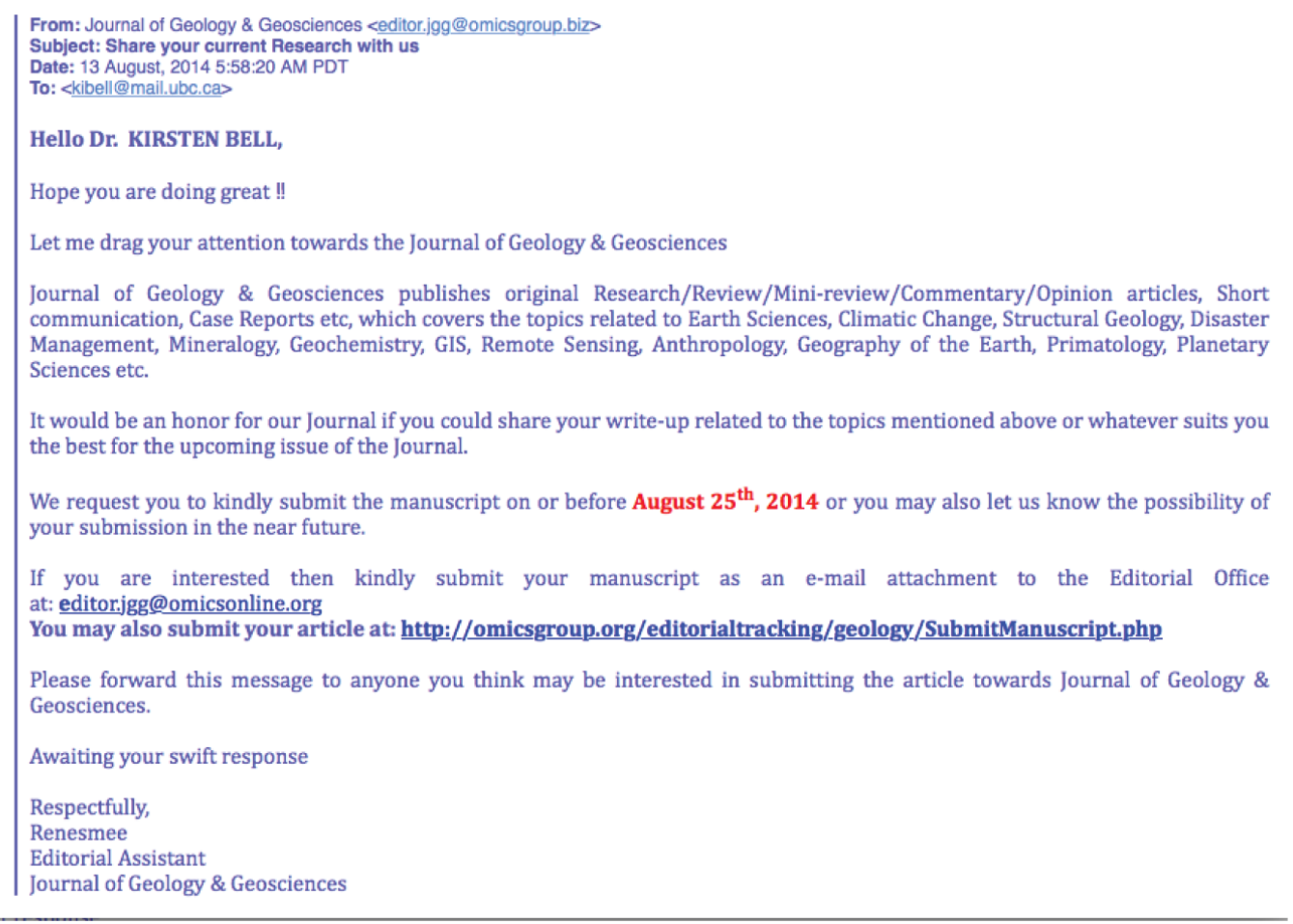

Figure 1. Email invitation from Journal of Geology \& Geosciences

\section{Introduction}

Today, academics are inundated with daily email invitations from a new breed of open access journals. Typically, these emails follow the same structure and format as an invitation I received from the Journal of Geology \& Geosciences (see Figure 1). Often featuring an idiosyncratic interpretation of what constitutes an academic field (e.g. anthropology as a geoscience), along with other red flags, these journals are the object of growing concern amongst academics and commentators.

Until recently, leading the charge was Jeffrey Beall, a librarian at the University of Colorado. Credited with coining the phrase 'predatory open access journal', Beall used the term to describe a distinct type of journal that exists exclusively to profit from the fees charged by mainstream publishers to make manuscripts openly accessible. According to Beall $(2013,591)$, "Many honest scholars have been seriously victimized by predatory publishers", and his website Scholarly Open Access: Critical Analysis of Scholarly Open-Access Publishing was devoted to exposing their activities. Containing his influential if controversial blacklist, it detailed hundreds of "potential, possible, or probable predatory scholarly open-access publishers".

Although his website closed in January 2017 under mysterious circumstances, it has effectively set the tone of debate around such journals, and the term 'predatory' has become the standard way to describe them. Indeed, the closure of his website has generated considerable consternation, the tenor of which is captured in a post on the popular academic blog The Conversation titled "Who will keep predatory science journals at bay now that Jeffrey Beall's blog is gone?" (Brown 2017). The shutdown of the blog was also covered on Science's website, which quoted an influential blogger stating that "Beall's list was extremely valuable because predatory journals are a huge problem" (Chawla 2017). In this framing, Beall is treated as the lone 
bulwark against the tide of predatory journals that would otherwise overrun academics.

\section{The Notion of the 'Predatory' Open Access Journal Goes Mainstream}

Although Beall started his list in 2008, the problem of 'predatory' open access journals came to wider attention in 2013 when Science published the results of a sting operation by John Bohannon (2013), a biologist and science journalist. Creating a credible but flawed paper by a group of fictitious African scholars, Bohannon used Beall's list and the Directory of Open Access Journals to identify 304 fee-based journals, which he then submitted the fake manuscript to. Of the 255 versions of the manuscript that underwent review, 157 journals accepted it and 98 rejected it. In the majority of cases, there was no discernible evidence of peer review.

Widely publicised, the results of the sting operation were represented by some commentators as a significant blow to the open access movement, confirming the lack of quality controls of open access journals. In a follow-up article vehemently condemning the movement, Beall argued:

We mustn't forget the strengths of the traditional or subscription model of scholarly journal publishing. When space was an issue, journals could only publish the very best of the articles they received, and any lapse in quality over time led to subscription cancellations. The result was that the traditional journals presented the cream of the crop of current research. With open-access journals, the opposite is often true. (Beall 2013, 596)

Others, however, pointed out that the sting operation did not target subscriptionbased journals, so it's unclear if their quality controls would have been any better. In the words of Michael Eisen (2013), an open access advocate and co-founder of the Public Library of Science, "It's nuts to construe this as a problem unique to open access publishing, if for no other reason than the study didn't do the control of submitting the same paper to subscription-based publishers".

Peter Suber (2013), another key figure in the open access movement, observed that Bohannon's exposé gave the impression that all or most open access journals impose article processing charges (APCs), even though the majority are free. ${ }^{1}$ Indeed, Bohannon intentionally targeted fee-based publishers, so the journals he selected were far from representative. As the librarian Paula Callan (2013) pointed out in a separate commentary, predatory publishers "represent less than two per cent of the 9,900 open access journals currently available. The majority of open access journals are run by not-for-profit scholarly societies, university presses, academic departments and geographically dispersed groups of academics". Thus, for many observers, both Bohannon and Beall seemed to be using the 'predatory journal' discourse as a cover for discrediting the open access movement more broadly (Bivens-Tatum 2014; Nwagwu 2016).

The debates generated by Bohannon's article reveal deep divisions regarding the current state and future direction of academic publishing. However, although there is disagreement over the size and scope of the problem of predatory publishers, players on both sides of the debate typically treat them as merely the 'dark side' of

${ }^{1}$ Of the 9437 journals listed in the DOAJ directory as of June 2017,5901 (63\%) do not have APCs. 
the open access movement (e.g., Masten and Ashcraft 2016). To quote Suber (2013), "Weak and dishonest OA journals give OA a bad name. I want to expose them. I want to warn authors and readers against them. I want to drive them from the field". In other words, the notion of a predatory open access journal has become a mainstream conceptualisation, regardless of individual academics' position on open access itself - a view, I suggest in what follows, that requires reconsideration.

\section{Drawing Lines Between 'Legitimate' and 'Predatory' Publishers}

As I have already noted, a key difference between a 'predatory' and 'legitimate' journal is typically seen to be the exclusive profit motive of the former. According to Margaret Kearney and the International Academy of Nursing Editors (known by the rather unfortunate acronym 'INANE') Predatory Publishing Practices Collaborative, "with profit as the driving force, these 'predatory publishers' engage in a range of disturbingly unethical and unscholarly practices with the goal of attracting author fees, offering little in return" $(2015,2)$. However, by claiming quality controls they don't necessarily provide and prioritising profit above all else, these journals arguably mirror, albeit in distorted form, the limitations of mainstream academic publishing itself.

Open access advocates frequently observe that the largest journal publishers have higher profit margins than the biggest oil companies - and have been equally ruthless in pursuing them (Monbiot 2011; Suber 2012). For example, in 2010, the publishing giant Elsevier made USD $\$ 1.1$ billion on revenues of $\$ 2$ billion - a profit margin of $36 \%$ (The Economist 2011). In 2015, it posted higher profit margins than Apple (Schmitt 2015). Thus, highlighting the profit motive of 'predatory' journals equally challenges the credibility of 'legitimate' publishers themselves. As Truth (2012) concludes in a piece on the rise of academic journal rackets:

[...] perhaps we are dealing with two kinds of 'rackets': established elite, based on extortionate subscriptions for individuals and institutions [...] and 'start-up' upstart OA predators, both a phenomenon of capitalist relations and forces of biopolitical knowledge production at the present explosive conjuncture (2012, 67; emphasis in original).

In light of these undeniable financial similarities, considerable intellectual weight is placed upon the quality controls implemented by mainstream publishers as a means of differentiating them from their illegitimate counterparts - especially peer review and indexation in accredited databases (Web of Science, Medline, Scopus, etc.), along with proxy quality indicators such as the journal impact factor. ${ }^{2}$ However, according to Ray (2016), parsing 'legitimate' from 'counterfeit' journals is a far more complicated task than Beall's list suggests. Indeed, librarians in her own institution (University of Mary Washington) expressed concerns about the inclusion of more than $25 \%$ of journals on Beall's list, pointing to difficulties in evaluating a journal's publication process from the outside or on the strength of individual published articles themselves.

${ }^{2}$ An impact factor can theoretically be calculated for any journal over three years of age; however, Web of Science (then the Institute for Scientific Information) invented it, so only the journals it indexes (e.g. Social Sciences Citation Index, Science Citation Index) can legally use it. 
As Eisen (2013) observes, publication venue alone is hardly a guarantor of quality, even when editorial standards and peer review processes are in place. Indeed, there is now a large body of literature on the problems with peer review, which includes extended studies such as Peerless Science (Chubin and Hackett 1990) and Peer Review: A Critical Inquiry (Shatz 2004), along with satirical websites (e.g., Shit My Reviewers Say ${ }^{3}$ ) and commentaries (e.g., Bell 2015a). According to Shatz, "The cumulative effect of the studies and of experience with peer reviewed articles is to suggest [...] that the system does not, in fact, always work. It suffers from widespread bias, subjectivity, and incompetence" $(2004,3)$. The biases of indexes and databases are also well documented. Prestigious indexes like the Social Sciences Citation Index (SSCI) have been characterised as ideological black boxes (Klein and Chang 2004), with a lack of transparency in their criteria for how journals are determined for inclusion and clear inconsistencies in those indexed. Such indexes have also been consistently shown to favour English-language and North American publications (Nieminem and Isohanni 1999; Archambault et al. 2006; Alperin 2014).

Likewise, studies have shown the limitations of the journal impact factor as a proxy for quality and its potential for misuse and abuse (Amin and Mabe 2004; Ha, Tan and Soo 2006). As Cooper and Poletti $(2011,60)$ have observed in a discussion of the growing institutional emphasis placed upon such indicators in the Australian context, "The result can only be, at the very least, a distortion of research behaviour as academics recognise and cynically (or desperately) respond to quality measurement regimes". Importantly, these distortions are increasingly being felt across the globe, as many non-Western countries now require academics to publish in international, English-language journals with a high impact factor in order to progress in their careers - a phenomenon Chou (2014) labels 'SSCI Syndrome'. According to Truth $(2012,58)$, "The tightening grip of knowledge commodification and the 'publish or perish' syndrome is extreme in the core higher-income economies [...] but has become a metastasizing phenomenon in virtually all".

All this would suggest that the 'predatory journal' discourse is a way of containing the larger questions that such publishers raise about mainstream knowledge production itself. However, if we view dodgy open access publishers as parody instead of predator, a rather different reading emerges - one that destabilises the prevailing discourse on what constitutes a 'legitimate' journal, and, indeed, the nature of scholarly knowledge production itself.

\section{4. 'Predatory' Journals as Parody}

As the recipient of dozens of email invitations per week from so-called predatory journals, I have observed that they often contain an almost satiric quality. Take, for example, the aforementioned invitation from the Journal of Geology \& Geosciences (see Figure 1). The name of the editorial assistant, 'Renesmee', was invented by Stephenie Meyer in her popular young adult series Twilight, so no adult alive bears the name (although some rather unfortunate children do). This is not an isolated phenomenon. For example, in his exposé, Bohannon reproduced the response he received from one 'Grace Groovy', after he (under the guise of the fictional African academic) requested that a publisher withdraw the fake manuscript. The cartoonishness of the respondent's name - which, as Bohannon himself acknowledges, sounds like a fictional character - seems to present more of a caricature of academic journals than an attempt to credibly mimic them.

\footnotetext{
${ }^{3}$ http://shitmyreviewerssay.tumblr.com/archive
} 
It is worth noting that despite the growth of the predatory journal discourse, many scholars treat invitations from these journals - and the academic conferences that have accompanied them - with amusement (and annoyance) rather than alarm. ${ }^{4}$ This is readily apparent on the Twitter \#academicspam hashtag, which is devoted to entertaining examples of the genre. A less malign view also underpins a recent article published in the British Medical Journal titled "We read spam a lot: prospective cohort study of unsolicited and unwanted academic invitations" (Grey et al. 2016). The piece is a parody of a scientific research paper and is structured exactly like one, with an overview of methods, a results section, a competing interests section, and so on. The authors classify spam emails into various categories such as 'spam dressed as lamb', 'tasty spam', 'stir-fried spam' and 'premium spam', and their competing interests section includes tongue-in-cheek statements such as:

ND almost joined the editorial board of Hair: Therapy and Transplantation but decided her hair was fabulous enough. GG is developing the Number Needed to Spam, an index of how many recipients need to be spammed to recruit one conference attendee. LS wishes henceforth to be addressed solely as Iconic Professor (Ibid., 4).

These accounts challenge Beall's rhetoric about the "serious victimization" of unsuspecting scholars and the prevailing view of these publishers as a significant problem. Clearly, if such journals are predators, they are not particularly effective ones. Instead, they seem to parody rather than straightforwardly replicate academic norms - for example, by exaggerating status hierarchies in academia through the use of obsequious and over-the-top language ("Dear Iconic Professor"). For this reason, their relationship with parody bears closer examination.

According to Dentith $(2000,6)$, "the discussion of parody is bedevilled by disputes over definition". He observes that some literary scholars see parody as a distinct genre that can be conceptually differentiated from satire, travesty, pastiche, spoof and burlesque, whereas others treat it as encapsulating a broad spectrum of practices. Hutcheon (2000), who has presented one of the more influential definitions, argues that what distinguishes parody is its use of ironic inversion. In her words, parody is "repetition with critical distance, which marks difference rather than similarity" (Ibid., 6). Thus, the difference between parody and repetition boils down to the question of intent, although Hutcheon acknowledges that this is "both complex and difficult to verify" (Ibid., 40). Hariman (2008), on the other hand, suggests that parody is best thought of as a combination of imitation and alteration. This definition has the advantage of moving us away from thorny questions of intent by shifting the focus to actions and effects.

To illustrate, Hariman describes an occasion when his 10-year-old daughter began to parrot his gestures and facial expressions at the dinner table. By throwing his style beyond its usual vehicle of expression, their stark differences in gender, social station and power turned her act of mimicry into a form of parody - regardless of his daughter's intention, the effect was to make him feel ridiculous in his own eyes. According to Hariman, this is the defining feature of parody: via its distortions, it serves to expose the limits of the original. In his words,

\footnotetext{
${ }^{4}$ I must confess to having done so myself on various occasions.
} 
What had seemed to be serious is in fact foolish, and likewise the powerful is shown to be vulnerable, the unchangeable contingent, the enchanting dangerous. Parody works in great part by exceeding the tacit limits on expression - the appropriate, the rational - but it does so to reveal limitations that others would want to keep hidden (Hariman 2008, 251).

As I have already illustrated, in their distinctive combination of mimicry and distortion, these journals reveal the limitations of mainstream publishers themselves, throwing up questions about where the lines between 'legitimate' and 'illegitimate' periodicals can be drawn. For Hariman, this destabilising potential is a critical function of parody - one that, in some instances, serves to erase the very binaries it exposes ${ }^{5}$ : "Once set beside itself, not only that discourse but the entire system is destabilized" (2008, 254). Indeed, this question of whether parody is an essentially subversive or conservative force has been extensively explored in the literature, although Dentith (2000) argues that its effects can't be evaluated in abstraction from the particular social and historical circumstances in which it is performed.

\section{North-South Relations, Mimicry and Parody}

One illustration of the potentially subversive effects of parody can be found in Homi Bhabha's (1984) work on colonial mimicry. ${ }^{6}$ According to Bhabha, the grand civilising mission that justified British colonialism produced "the desire for a reformed, recognizable Other, as a subject of difference that is almost the same, but not quite" - i.e. "almost the same, but not white" (Ibid., 130). In other words, the goal of British colonial policy was to create subjects who were British in mode and thought, yet not so British that they thought of themselves as equals. Imitation was desired, but only insofar as it didn't challenge British rule itself.

As Bhabha deftly illustrates, the fundamental ambivalence of the discourse on colonial mimicry produced a slippage that meant that mimicry was both resemblance and menace - simultaneously legitimising and discrediting colonial rule. To quote Ferguson $(2002,553)$, "colonial imitation always threatened to become excessive and uncontrolled and thereby to unsettle the boundaries and relations of authority between settler and native that the colonial order depended on". Thus, mimicry was also a sign of the inappropriate, of a difference that intensified colonial surveillance and posed a threat to its "'normalized' knowledges and disciplinary powers" (Bhabha 1984, 126).

This example resonates with the present case on a variety of levels, not least because of the composition of so-called predatory journals. One of the most significant but sidestepped aspects of the rise of 'predatory' publishing is the evidence that many such journals emanate from the global South (Bohannan 2013; Shen and Björk 2015). This is apparent in Bohannon's Science article: the journals that were most likely to accept the fake manuscript were clustered in India, followed by Nigerian-based journals. But it's also clear that these countries dominate in terms of who is publishing in such journals - something Bohannon implicitly recognises

${ }^{5}$ Here, Hariman's arguments are strongly influenced by Bakhtin's (1984) work on the carnivalesque.

${ }^{6}$ At least, according to Hariman's definition of parody as imitation and alteration; colonial mimicry fits less clearly with Hutcheon's emphasis on parody as ironic inversion, although later accounts of 'mimesis' often treat this as a core feature (Ferguson 2002). 
(given that he chose to submit the fake paper in the name of a group of African scholars) but never directly addresses.

Several subsequent studies have confirmed the over-representation of Southern authors in 'predatory' journals. Xia et al. (2015) compared publishing patterns in seven journals from Beall's list with those in more respected open access journals (e.g., the PLoS collection). They found that most scholars publishing in the former journals were "concentrated in a few countries, such as India, Nigeria, and Pakistan" (Ibid., 1413), whereas more established journals were dominated by authors from the global North. Also using Beall's list, Shen and Björk (2015) sampled 613 journals and similarly found that the majority of authors came from the global South. When they compared the volume of 'predatory' publication in each country with the production of articles published in 'legitimate' international journals, their results were even more striking: "For the four biggest contributors of predatory articles, the USA had a low ratio of $6 \%$, Iran $70 \%$, India $277 \%$ and Nigeria a staggering 1,580\%" (Ibid., 14). In other words, Shen and Björk's findings suggest that the vast majority of scholarship produced by Nigerian researchers is being published in 'predatory' journals. This implies that such journals are providing a critical distribution channel for Nigerian academics (along with those in India and other countries in the global South), especially given that their APCs are typically affordable for local scholars and institutions. $^{7}$

In a recent article, Nwagwu and Ojemeni (2015) shed further light on the Nigerian context. Analyzing 5,601 papers published in 32 biomedical open access journals produced by two Nigerian publishers (Academic Journals and International Research Journals), they found that academics contributing to these journals came primarily from Asia, Africa and Europe. Nwagwu and Ojemeni also analysed the citation patterns for articles published in these journals and found that papers were being cited outside their countries of origin, with an average of 2.25 citations per paper. Thus, although only two of the publications they examined were indexed in Web of Science databases, their visibility in Google Scholar meant that papers were being found and read. ${ }^{8}$ In consequence, Nwagwu and Ojemeni $(2015,30)$ suggest that such scholarship "is beginning to appear visible to the world, even when published in journals that may be considered outside the acceptable criteria for publishing", in a way that has not previously been witnessed.

Nwagwu and Ojemeni (2015) speculate that Southern scholars are attracted to these journals for a variety of reasons: their speed of publication, the elitism of accredited (i.e., Northern) journals and the difficulty of negotiating the mainstream journal environment for those researchers who are early in their careers or for whom English is a problem, and the challenges of paying the APCs of mainstream open access journals. Likewise, Truth (2012) argues that such journals are largely driven by the internationalisation of scientific research and the emergence of an underclass

${ }^{7}$ As Shen and Björk (2015) and Xia et al. (2015) show, the APCs of so-called 'predatory' journals are typically an order of magnitude smaller than those charged by mainstream publishers. Moreover, these journals often have a different fee structure depending on authors' location (and, in some cases, career stage), with scholars in Northern institutions charged a higher fee than those in Southern ones. This alone would suggest that such journals are primarily aiming to attract Southern scholars.

${ }^{8}$ At first glance, this seems to contradict Xia et al. (2015), who found that citation rates for papers published by 'predatory' journals were significantly lower than for other groups of open access journals; however, lower citation rates don't entirely preclude the possibility of citation. 
of scholars in the global South who don't have the resources to compete with their more privileged Northern counterparts. Although he condemns such journals as inherently exploitative, Truth suggests that they should be viewed as a kind of subalternised space within cognitive capitalism and the materialities of knowledge production.

Nwagwu and Ojemeni (2015), however, are less convinced that these journals are always exploitative. They point out that some of the periodicals Beall has attacked are sincere initiatives, although their packaging, presentation and quality may be lacking. As Nwagwu (2016) asks:

What would one expect of scholars and publishers from parts of the world where print publishing has never flourished as a result of economic and other limitations? If a technology develops that enables them to bypass the obstacles posed by the print technology, should they not use it? What would be expected of scholars whose research efforts are often rejected by scholars from developed countries due to the limitations of language and other quality criteria? (Nwagwu and Ojemeni 2015, 71)

Taken together, the results of these studies indicate that the prevailing view of such journals as merely 'predators' and authors as merely 'victims' is a serious oversimplification of a much more complicated issue. Indeed, given the implicitly racialised profile of these publications, the 'predatory' journal discourse starts to bear an uncomfortable resemblance to the discourse on colonial mimicry, with such journals - and the scholars who publish in them - becoming synonymous with an implicit academic Other ${ }^{9}$ (almost the same, but not right; almost the same, but not white). Here, mimicry becomes a sign of the inappropriate, of a difference that intensifies surveillance in much the same way as colonial mimicry itself. Thus, as Truth (2012) and Nwagwu (2016) point out, one of the dangers of the 'predatory' journal discourse is its potential to disguise a racist subtext that reproduces the coloniality of power/knowledge.

Typically, where this larger context is recognised, it is treated as a consequence of the publishing landscape in the authors' own countries and their embrace of a 'publish or perish' mentality. To quote a recent editorial in the British Medical Journal on this topic: "Research institutions in low and middle income countries must improve the oversight, training, and mentorship needed to optimize publication literacy, especially among junior researchers" (Clark and Smith 2015). In this way, the problem becomes 'theirs', not 'ours', and the response is one of disciplining and surveillance - more benignly writ as 'training' and 'oversight'.

The issue is that such characterisations leave the larger global structure of knowledge production unchallenged. As Shen and Björk $(2015,14)$ observe: "these

${ }^{9}$ In some contexts, this is quite explicit. A perfect example is Impact Factor Services for International Journals (IFSIJ), an Indian-based organisation that operates an indexing and impact-factor measuring service for international journals. For an annual fee of USD $\$ 40$, 'predatory' journals can have their impact factor evaluated according to IFSIJ's method and list it on their website. Although roundly condemned by Beall and other commentators (e.g., Jalalian 2015), these kinds of organisations arguably reveal the impact factor for precisely what it is: a fetishised and vacuous number (Bell 2015b). 
authors and their institutions are part of a structurally unjust global system that excludes them from publishing in 'high quality' journals on the one hand and confines them to publish in dubious journals on the other". Thus, if we instead view 'predatory' journals through the lens of Bhabhian mimicry, they are revealed not as an aberration but as actively produced by the prevailing logic and structure of global knowledge production. And like colonial mimics, these journals serve to expose - and thereby potentially unsettle - the relations of authority that traditional forms of scholarly publishing depend on. After all, for Bhabha, "mimicry, like the fetish, is a part-object that radically revalues the normative knowledges of the priority of race, writing, history. For the fetish mimes the forms of authority at the point at which it deauthorizes them" (1984, 131-132).

\section{Conclusion}

Although the concept of 'predatory' open access journals has been widely taken up, it serves to limit our understanding of what is a far more interesting and complex phenomenon. In particular, I have suggested that it is more useful to think of these publishers as parody (and mimicry in Bhaba's sense) rather than predator. Without wishing to deny the questionable ethics of some of these publishers, they nevertheless expose the problems with contemporary knowledge production in academia, in terms of its commercial context, our methods for ascertaining quality and value, and the ways it systematically privileges scholarship from the 'centre' and marginalises and excludes that from the 'periphery'. Viewed in this light, such journals reveal not the dark side of the open access movement, but the dark side of academic knowledge production itself and the underlying truth of "the democratic, egalitarian ethos of scientists [...] as the visible face of a hierarchical system echoing the structure of feudal nobility" (Guédon 2001, 10).

\section{References}

Alperin, Juan. 2014. South America: Citation Databases Omit Local Journals. Nature 511: 155.

Amin, Mayur and Michael A. Mabe. 2004. Impact Factors: Use and Abuse. International Journal of Environmental Science and Technology 1(1): 1-6. Accessed September 12, 2016. http://www.scielo.org.ar/scielo.php?script=sci arttext\&pid=S002576802003000400011

Archambault, Éric, Étienne Vignola-Gagné, Grégoire Côté, Vincent Larivière and Yves Gingras. 2006. Benchmarking Scientific Output in the Social Sciences and Humanities: The Limits of Existing Databases. Scientometrics 68(3): 329-342.

Bakhtin, Mikhail. 1984. Rabelais and His World. Translated by Hélène Iswolsky. Bloomington: Indiana University Press.

Beall, Jeffrey. 2013. The Open-Access Movement is Not Really About Open Access. tripleC: Communication, Capitalism \& Critique. Open Access Journal for a Global Sustainable Information Society. 11(2): 589-597. Accessed September 5, 2016. http://www.triplec.at/index.php/tripleC/article/viewFile/525/514

Bell, Kirsten. 2015a. How to Review a Journal Article. Centre for Imaginative Ethnography. Accessed July 1, 2015. http://imaginativeethnography.org/imaginings/laughingmatters/how-to-review-a-journal-article/

Bell, Kirsten. 2015b. Journal Standards and Their Stories: Or, a Trip Down the Rabbit Hole. Medicine Anthropology Theory 2 (3): 182-189. Accessed January 15, 2016. http://www.medanthrotheory.org/read/5520/journal-standards

Bhabha, Homi. 1984. Of Mimicry and Man: The Ambivalence of Colonial Discourse. Discipleship 28: 125-133. 
Bivens-Tatum, Wayne. 2014. Reactionary Rhetoric Against Open Access Publishing. tripleC: Communication, Capitalism \& Critique. Open Access Journal for a Global Sustainable Information Society. 12 (2): 441-446. Accessed February 23, 2017. http://www.triplec.at/index.php/tripleC/article/view/617/572

Bohannon, John. 2013. Who's Afraid of Peer Review? Science 342(6154): 60-65. Accessed August 12, 2016. http://science.sciencemag.org/content/342/6154/60.full

Brown, Michael J.I. 2017. Who Will Keep Predatory Science Journals at Bay Now That Jeffrey Beall's Blog is Gone? The Conversation, 19 January. Accessed January 20, 2017. http://theconversation.com/who-will-keep-predatory-science-journals-at-bay-now-thatjeffrey-bealls-blog-is-gone-71613

Callan, Paula. 2013. Fake Paper Highlights Predatory Publishers. ABC News, 10 April. Accessed August 23, 2016. http://www.abc.net.au/science/articles/2013/10/04/3862443.htm

Chawla, Dalmeet Singh. 2017. Mystery as Controversial List of Predatory Publishers Disappears. Science [Magazine], 27 January. Accessed January 27, 2017. http://www.sciencemag.org/news/2017/01/mystery-controversial-list-predatory-publishersdisappears

Chou, Chuing Prudence, ed. 2014. The SSCI Syndrome in Higher Education: A Local or Global Phenomenon. Rotterdam: Sense Publishers.

Chubin, Daryl E. and Edward J. Hackett. 1990. Peerless Science: Peer Review and U.S. Science Policy. New York: SUNY Press.

Clark, Jocalyn and Richard Smith. 2015. Firm Action Needed on Predatory Journals. British Medical Journal 350: h210.

Cooper, Sara and Andrew Poletti. 2011. The New ERA of Journal Ranking. Australian Universities' Review 35 (1): 57-65. Accessed October 5, 2013. http://www2.warwick.ac.uk/fac/sci/psych/people/jtresilian/jtresilian/cooperandpoletti.pdf

Dentith, Simon. 2000. Parody. London: Routledge.

Eisen, Michael. 2013. Open Access is Not the Problem: My Take on Science's Peer Review 'Sting'. Berkeley Blog, 4 October. Accessed August 23, 2016. http://blogs.berkeley.edu/2013/10/04/open-access-is-not-the-problem/

Ferguson, James G. 2002. Of Mimicry and Membership: Africans and the 'New World Society'. Cultural Anthropology 17 (4): 551-569.

Grey, Andrew, Mark J. Bolland, Nicola Dalbeth, Greg Gamble and Lynn Sadler. 2016. We Read Spam a Lot: Prospective Cohort Study of Unsolicited and Unwanted Academic Invitations. British Medical Journal 355: i5383. Accessed February 19, 2017. http://www.bmj.com/content/355/bmj.i5383

Guédon, Jean-Claude. 2001. In Oldenburg's Long Shadow: Librarians, Research Scientists, Publishers, and the Control of Scientific Publishing. Washington, DC: Association of Libraries.

$\mathrm{Ha}$, Tam C., Say Beng Tan and Khee Chee Soo. 2006. The Journal Impact Factor: Too Much of an Impact? Annals of Academic Medicine Singapore 35: 911-916. Accessed August 13, 2016. http://www.annals.edu.sg/pdf/35VolNo12Dec2006/V35N12p911.pdf

Hariman, Robert. 2008. Political Parody and Public Culture. Quarterly Journal of Speech 94(3): 247-272.

Hutcheon, Linda. 2000. A Theory of Parody: The Teachings of Twentieth-Century Art Forms. Chicago: University of Illinois Press.

Jalalian, Mehrdad. 2015. The Story of Fake Impact Factor Companies and How We Detected Them. Electronic Physician 7 (2): 1069-1072. Accessed June 14, 2017. https://www.ncbi.nlm.nih.gov/pmc/articles/PMC4477767/

Kearney, Margaret H. and the INANE Predatory Publishing Practices Collaborative. 2015. Predatory Publishing: What Authors Need to Know. Research in Nursing and Health 38: 1-3. Accessed January 10, 2017. 
http://journals.Iww.com/aenjournal/Fulltext/2015/01000/Predatory Publishing What Edit ors Need to Know.1.aspx

Klein, Daniel B. and Eric Chiang. 2004. The Social Science Citation Index: A Black Box With An Ideological Bias? Economic Journal Watch 1 (1): 134-165. Accessed September 13, 2017. https://econjwatch.org/file download/263/ejw ia apr04 kleinchiang1.pdf?mimetype=pdf

Masten, Yondell B. and Alyce S. Ashcraft. 2016. The Dark Side of Dissemination: Traditional and Open Access Versus Predatory Journals. Nursing Education Perspectives 37 (5): 275-277. Accessed January 10, 2017. http://pubmedcentralcanada.ca/pmcc/articles/PMC4998130/

Monbiot, George. 2011. Academic Publishers Make Murdoch Look Like a Socialist. The Guardian, 29 August. Accessed January 26, 2016.

https://www.theguardian.com/commentisfree/2011/aug/29/academic-publishers-murdochsocialist

Nieminem, Pentti and Matti Isohanni. 1999. Bias Against European Journals in Medical Publication Databases. The Lancet 353 (9154): 1592.

Nwagwu, Williams Ezinwa. 2016. Open Access in the Developing Regions: Situating the Altercations About Predatory Publishing. Canadian Journal of Information and Library Science 40 (1): 58-80.

Nwagwu, Williams Ezinwa and Obinna Ojemeni. 2015. Nigerian Predatory Biomedical Open Access Journals 2007-2012: A Bibliometric Study. Learned Publishing 28 (1): 23-34.

Ray, Margaret. 2016. An Expanded Approach to Evaluating Open Access Journals. Journal of Scholarly Publishing 47 (4): 307-327.

Schmitt, Jason. 2015. Can't Disrupt This: Elsevier and the 25.2 Billion Dollar a Year Academic Publishing Business. Medium, 22 December. Accessed June 14, 2017. https://medium.com/@jasonschmitt/can-t-disrupt-this-elsevier-and-the-25-2-billion-dollara-year-academic-publishing-business-aa3b9618d40a

Shatz, David. 2004. Peer Review: A Critical Inquiry. Lanham, MD: Rowman \& Littlefield.

Shen, Cenyu and Bo-Christer Björk. 2015. 'Predatory' Open Access: A Longitudinal Study of Article Volumes and Market Characteristics. BMC Medicine 13: 230. Accessed August 30, 2016. http://bmcmedicine.biomedcentral.com/articles/10.1186/s12916-015-0469-2

Suber, Peter. 2013. New "Sting" of Weak Open-Access Journals. Google+, 3 October. Accessed August 30, 2016. https://plus.google.com/u/0/+PeterSuber/posts/CRHeCAtQqGq

Suber, Peter. 2012. Open Access. Cambridge, MA: The MIT Press. https://www.dropbox.com/s/5cxsyzs58a5yx5q/9286.pdf?dl=0

The Economist. 2011. Academic Publishing: Of Goats and Headaches. May 26. Accessed June 15, 2017. http://www.economist.com/node/18744177/

Truth, Frank. 2012. Pay Big to Publish Fast: Academic Journal Rackets. Journal for Critical Education Policy Studies 10 (2): 54-105. Accessed August 31, 2016. http://www.jceps.com/wp-content/uploads/PDFs/10-2-02.pdf

Xia, Jingfeng, Jennifer L. Harmon, Kevin G. Connolly, Ryan M. Donnelly, Mary R. Anderson and Heather A. Howard. 2015. Who Publishes in 'Predatory' Journals? Journal of the Association for Information Science and Technology 66 (7): 1406-1417.

\section{About the author}

Kirsten Bell

Kirsten Bell received her PhD in social anthropology in 2000 from James Cook University in Australia. She is an Honorary Associate in the Department of Anthropology at the University of British Columbia and has published widely on the anthropology of public health. Her sixyear editorial stint with a subscription-based academic journal has convinced her of the limitations of this model, and she is currently completing a Master of Publishing at Simon Fraser University to explore alternative approaches to scholarly publishing. 